\title{
Effect of Osteoporosis Prevention Programme on Knowledge among Elderly People
}

\author{
*Corresponding Author \\ Sahbanathul Missiriya Jalal \\ Article History \\ Received: 17.12 .2020 \\ Accepted: 31.12 .2020 \\ Published: 13.01.2021
}

Sahbanathul Missiriya Jalal ${ }^{*}$

Ph.D, RN., Assistant Professor, Nursing Department, College of Applied Medical Sciences, King Faisal University, AlAhsa, Kingdom of Saudi Arabia

\begin{abstract}
Objectives: Osteoporosis is an asymptomatic disease characterized by low bone mass and loss of the quality of bone, which increases the risk of a bone fracture. This is the most common reason for a broken bone among the geriatric population. Educational intervention is ideal for osteoporosis because many of its risk factors can be treated, such as poor dietary calcium intake and limited amounts of physical activity. This study aimed to determine the effect of the prevention program on knowledge regarding osteoporosis among geriatrics and to associate the level of knowledge with selected demographic variables. Materials and Methods: Pre-experimental design adopted. Totally 60 geriatric people aged $>60$ years visited the selected chronic outpatient clinic were selected by using a convenient sampling technique. The data collected through a structured questionnaire to measure knowledge regarding osteoporosis. The educational awareness program was conducted as a group for 30 minutes. The pre-test and post-test scores were analyzed, in terms of both descriptive and inferential statistics. Results: Out of 60 samples $15 \%$ \& $55 \%$ had adequate knowledge, $61.7 \%$ \& $40 \%$ people had average knowledge and $23.3 \%$ \& 5\% had inadequate knowledge in pre and posttest. The paired ' $t$ ' test value 6.5147 is highly significant $(\mathrm{P}<0.01)$ which proved the effectiveness of osteoporosis prevention programme (OPP). There was a significant association found between the level of knowledge and education and BMI at $P<.05$ level. Conclusion: Prevention is the most effective method of decreasing the morbidity and mortality of osteoporosis. Nurses have a major impact on educating geriatrics about the risks for osteoporosis.
\end{abstract}

Keywords: Osteoporosis Prevention Programme; Effect; Knowledge; Elderly People.

\section{INTRODUCTION}

Ageing is a biological process of growing old during which structural and functional changes will occur. The age of 60-65 years is the beginning of old age and people get retirement from work [1]. The biological process of ageing associated with progressive degeneration of the tissues which impacts the accumulation of a wide variety of molecular and cellular damage. This leads to a gradual decrease in physical and mental capacity causing the risk of diseases and its complications, results in death for some people. However, these changes are loosely associated with a person's age in years and they are neither linear nor consistent [2].

Since the proportion of the world's population especially whose aged $>60$ years will double in the next four decades. This will be accompanied by an increased incidence of chronic age-related diseases such as chronic obstructive pulmonary disease (COPD), diabetes, hypertension, depression, and congestive heart failure that will place a huge burden on healthcare resources [3].

During the process of ageing, there is increased bone resorption and decreased bone formation. This is opposite to the normal turnover of bone occurring in a healthy young skeleton, in which the rate of bone resorption and matrix degradation is matched by bone formation and matrix mineralization [4]. Moreover, ageing affects the formation of the active form of vitamin $\mathrm{D}$ which affects the adequate absorption of calcium, which result in osteoporosis [5, 6].

Copyright (C) 2020 The Author(s): This is an open-access article distributed under the terms of the Creative Commons Attribution 4.0 International License (CC BY-NC 4.0) which permits unrestricted use, distribution, and reproduction in any medium for noncommercial use provided the original author and source are credited. 
Osteoporosis is a chronic skeletal disease, characterized by bone fragility due to deterioration of the bone microarchitecture and reduction of bone mass and, resulting in an increased risk of fracture [7]. Many of the risk factors for osteoporosis in the general population are features of COPD including advanced age, smoking, low physical activity levels, and low body weight. Thus, the prevalence of osteoporosis is highly associated in patients with COPD and low body mass index $[8,9]$.

Moreover, 34 million people were having osteoporosis, with low bone mass in the United States. In which, the elderly population aged at least 65 years, accounts for most of the burden, with $70 \%$ of all fractures [10, 11]. In Kingdom of Saudi Arabia, at a national level, the prevalence of osteoporosis and osteopenia (either spine or femur) and revealed a prevalence of $37.8 \%$ and $54.1 \%$, respectively, in Jeddah; $37.4 \%$ and $33.9 \%$, respectively, in Al Khobar, and $21.4 \%$ and $35.7 \%$, respectively, in Riyadh [12, 13]. Particularly, vitamin D deficiency is extremely common among Saudis overall, more in females. This was attributed to the dressing customs and avoidance of sun exposure. This fact might have confounded by many studies on osteoporosis in Saudi Arabia [14]. Awareness and knowledge about any disease is the first step to prevent and treat it, so this study aimed to determine the effect of osteoporosis prevention program (OPP) on knowledge among geriatrics and to associate the level of knowledge with selected demographic variables.

\section{MATERIALS AND METHODS}

In a pre-experimental research design, one group pre-test post-test method was used to assess the effect of the prevention program on knowledge regarding osteoporosis among the geriatrics population. The research was carried out in chronic out-patient clinics of selected health centers. Totally 60 geriatric people aged $>60$ years were selected by using a convenient sampling technique. The data collected through a structured questionnaire to measure knowledge regarding osteoporosis. The tool consists of demographic variables which include age, gender, education, occupation, family type, family history of DM, duration of DM, and treatment methods adopted, and structured questionnaire on knowledge assessed by using 20 items based on multiple-choice questions which were developed from various available literature related to osteoporosis. According to the data plan, the data was collected from the sample after obtaining informed consent. After the pre-test, OPP as an educational awareness was conducted as a group consisting of 10 people for 30 minutes.

The scores were categorized as follows; they were below 50\% indicates inadequate knowledge, 50-75\% shows average knowledge and above $75 \%$ is considered as adequate knowledge. The collected data were analyzed by using descriptive and inferential statistics by using Statistical Package for Social Sciences (SPSS) package version 22, which includes number frequency, mean, standard deviation, and chi-square test for statistical analysis.

\section{RESULTS}

The study results showed that among 60 geriatrics people majority $28(46.7 \%)$ were between the age of 60-65 years, $17(28.3 \%)$ were between the age of 66-70 years, nine (15\%) were in 71-75 years and six (10\%) were in more than 75 years. The mean age of the people was 67.07 \pm 5.6 years. Regarding gender, $21(35 \%)$ were men and $39(65 \%)$ were women. About educational status, $12(20 \%)$ studied up to primary level, 19 (31.7\%) were studied up till high school, 18 $(30 \%)$ educated up to higher secondary level and $11(18.3 \%)$ were graduates. Twelve people $(20 \%)$ were involved in the job. Considering the body mass index (BMI) of the people, six (10\%) were underweight, $13(21.7 \%)$ were normal BMI, $24(40 \%)$ were overweight and $17(28.3 \%)$ were obese. Eighteen $(30 \%)$ were belonging to nuclear type and the remaining $42(70 \%)$ were in joint family type. Among them, 39 (65\%) were having a history of osteoporosis.

Most of the people $41(68.3 \%)$ were non-smokers, three $(5 \%)$ were past smokers and $16(26.7 \%)$ were current smokers. Nine $(15 \%)$ were having a history of cardiac problems, $18(30 \%)$ having COPD, $14(23.3 \%)$ hypertension, and $19(31.7 \%)$ having diabetes mellitus. Regarding source of health information, $23(38.4 \%)$ received from mass media, 20 $(33.3 \%)$ from health care professionals, eight (13.3\%) from family members, and nine (15\%) from friends.

Table-1: Frequency distribution of Knowledge level of geriatric population regarding osteoporosis in pre and post-test $(n=60)$

\begin{tabular}{|l|l|l|l|l|l|}
\hline \multirow{2}{*}{ Level of Knowledge } & \multirow{2}{*}{ Score } & \multicolumn{2}{|l|}{ Pre -test } & \multicolumn{2}{l|}{ Post test } \\
\cline { 3 - 6 } & & $\mathbf{N}$ & $\mathbf{\%}$ & $\mathbf{N}$ & $\mathbf{\%}$ \\
\hline Inadequate Knowledge & $<50 \%$ & 14 & 23.3 & 3 & 5 \\
\hline Moderate Knowledge & $50-75 \%$ & 37 & 61.7 & 24 & 40 \\
\hline Adequate Knowledge & $>75 \%$ & 9 & 15 & 33 & 55 \\
\hline
\end{tabular}

$N$-number; \%-Percentage

The study result showed that out of 60 samples nine of them (15\%) had adequate knowledge, $37(61.7 \%)$ people had average knowledge and $14(23.3 \%)$ had inadequate knowledge in pre-test and $33(55 \%)$ had adequate knowledge, 24 $(40 \%)$ members had average knowledge and three $(5 \%)$ had inadequate knowledge in post-test after conduction of OPP. 
Table-2: Paired ' $t$ ' test of osteoporosis prevention programme on knowledge in geriatric population $(\mathrm{n}=60)$

\begin{tabular}{|l|l|l|l|l|l|l|}
\hline $\begin{array}{l}\text { Knowledge } \\
\text { Level }\end{array}$ & Mean & $\begin{array}{l}\text { Standard } \\
\text { Deviation }\end{array}$ & $\begin{array}{l}\text { Mean } \\
\text { Difference }\end{array}$ & $\begin{array}{l}\text { Degrees of } \\
\text { freedom }\end{array}$ & $\begin{array}{l}\text { Paired 't' test } \\
\text { value }\end{array}$ & $p$-value \\
\hline Pre-test & 11.27 & 3.2 & 0.593 & 118 & 6.5147 & $p<.00001^{*}$ \\
\hline Post-test & 15.13 & 3.29 & & & \\
\hline
\end{tabular}

*Significant

Table number 2 illustrates that the mean post-test knowledge score 15.13 is higher than the mean pre-test knowledge score 11.27. The mean difference between pre-test and post-test score of 3.86. The paired ' $t$ ' test value 6.5147 is highly significant $(\mathrm{P}<0.01)$. Hence the study findings revealed that OPP on knowledge was effective in increasing the knowledge of the geriatric population.

The chi-square test reveals that there was a significant association found between the level of knowledge and education and BMI at $P<.05$ level.

\section{DISCUSSION}

In the current study, most of the study participants were $28(46.7 \%)$ were between the age of $60-65$ years, and the mean age of the people was $67.07 \pm 5.6$ years with $65 \%$ women. This was found in another study the mean age of the sample was $70.5 \pm 9.3$ years with $91.6 \%$ women [15]. The mean score of BMI was $26.5 \pm 4.87$ in this study which was different $(24.2 \pm 2.1)$ in another study [16].

The effect of OPP on knowledge was evaluated among the geriatric population in this study. There were many studies conducted on the effectiveness of educational programs towards knowledge regarding osteoporosis [15, 16]. In Australia, the osteoporosis prevention and self-management course was developed and administered for four weeks. The finding evidenced that there was an increase in participant's knowledge after providing osteoporosis intervention to the participants [17].

The mean difference between pre-test and post-test score was 3.86 in the present study. The mean change in knowledge score of 1.1 observed in a similar study which shows that the increase in knowledge following the education [18]. According to a study conducted on osteoporosis education improves osteoporosis knowledge and dietary calcium: comparison of a 4 week and a one-session education course, the results evidenced that comparing four weeks and a onesession course, both helped to improve osteoporosis knowledge however four weeks course only helped to decline the use of osteoporosis medications [19].

The most effective intervention motivated individuals to change their related behaviours. Another research showed that the osteoporosis knowledge did not lead to changes in their behaviours [20]. In this present study, there was a significant association observed between the level of knowledge and education and BMI at $P<.05$ level. There was a significant relationship between the level of knowledge and education, still, the relationship between education level and osteoporosis-related life habits were not significant. The relationship of osteoporosis-related life habits and awareness of osteoporosis and its risk factors was significant but there was no significant relationship of osteoporosis-related life habits and preventive factors [21, 22]. Another study results showed that Iranian women with a higher education level have significantly better knowledge about osteoporosis than women with a lower educational level, like the Chinese women in Singapore and Salvadoran women in Brazil [23].

\section{Study Limitations}

There are some limitations to this study. The sample size was small, and the prevalence of osteoporosis was not obtained. Also, the study did not include the practice of people regarding the prevention of osteoporosis. The selected demographic factors didn't further analyses for the correlation of self-efficacy of people. The study can be conducted as an experimental study with the control group in future researches.

\section{CONCLUSION}

In conclusion, prevention is the most effective method of decreasing the morbidity and mortality of osteoporosis. Effective educational intervention is important in increasing osteoporosis knowledge among Saudi people. Nurses have a major impact on educating geriatrics about the risks for osteoporosis to reduce future complications. Awareness through educational intervention is important in the prevention or treatment of chronic diseases such as osteoporosis. Therefore, it will contribute to reducing the burden of diseases, and mortality rates. OPP must provide opportunities for osteoporosis education at the national level for all geriatric population.

\section{Ethics}


Ethics Committee Approval: This study has been evaluated and approved by the department scientific committee, King Faisal University.

Informed Consent: Informed consent form was not taken from all the study participants.

Peer-review: Internally peer-reviewed.

Financial Disclosure: The author declared that this study received no financial support.

\section{REFERENCES}

1. Ahmed, A., \& Tollefsbol, T. (2001). Telomeres and telomerase: basic science implications for aging. Journal of the American Geriatrics Society, 49(8), 1105-1109.

2. Campisi, J. (2003). Cellular senescence and cell death. In: Timiras, P. S., editor. Physiological basis of aging and geriatrics. 3rd ed. CRC; Boca Raton, FL: CRC, 2003, 47A59.

3. Fisher, H. M., \& McCabe, S. (2005). Managing chronic conditions for elderly adults: the VNS CHOICE model. Health Care Financing Review. 27(1):33-45.

4. Papaioannou, A., Kennedy, C. C., Cranney, A., Hawker, G., Brown, J. P., Kaiser, S. M., ... \& Siminoski, K. (2009). Risk factors for low BMD in healthy men age 50 years or older: a systematic review. Osteoporosis international, 20(4), 507-518.

5. Gallagher, J. C. (2013). Vitamin D and aging. Endocrinology and Metabolism Clinics of North America. 42:319332.

6. Bolton, C. E., Ionescu, A. A., Shiels, K. M., Pettit, R. J., Edwards, P. H., Stone, M. D., ... \& Shale, D. J. (2004). Associated loss of fat-free mass and bone mineral density in chronic obstructive pulmonary disease. American journal of respiratory and critical care medicine, 170(12), 1286-1293.

7. Waugh, E. J., Lam, M. A., Hawker, G. A., McGowan, J., Papaioannou, A., Cheung, A. M., ... \& Jamal, S. A. (2009). Risk factors for low bone mass in healthy 40-60 year old women: a systematic review of the literature. Osteoporosis international, 20(1), 1-21.

8. Maggi, S., Siviero, P., Gonnelli, S., Schiraldi, C., Malavolta, N., Nuti, R., ... \& EOLO Study Group. (2009). Osteoporosis risk in patients with chronic obstructive pulmonary disease: the EOLO study. Journal of Clinical Densitometry, 12(3), 345-352.

9. Ferguson, G. T., Calverley, P. M., Anderson, J. A., Jenkins, C. R., Jones, P. W., Willits, L. R., ... \& Celli, B. (2009). Prevalence and progression of osteoporosis in patients with COPD: results from the TOwards a Revolution in COPD Health study. Chest, 136(6), 1456-1465.

10. Burge, R., Dawson- Hughes, B., Solomon, D. H., Wong, J. B., King, A., \& Tosteson, A. (2007). Incidence and economic burden of osteoporosis- related fractures in the United States, 2005-2025. Journal of bone and mineral research, 22(3), 465-475.

11. Curtis, J. R., \& Safford, M. M. (2012). Management of osteoporosis among the elderly with other chronic medical conditions. Drugs \& aging, 29(7), 549-564.

12. Al-Turki, H. A., Sadat-Ali, M., Al-Elq, A. H., Al-Mulhim, F. A., \& Al-Ali, A. K. (2008). 25-Hydoxyvitamin D levels among healthy Saudi Arabian women. Saudi Med J, 29(12), 1765-1768.

13. Ardawi, M. S. M., Maimany, A. A., Bahksh, T. M., Nasrat, H. A., Milaat, W. A., \& Al-Raddadi, R. M. (2005). Bone mineral density of the spine and femur in healthy Saudis. Osteoporosis International, 16(1), 43-55.

14. Al-Daghri, N. M. (2018). Vitamin D in Saudi Arabia: prevalence, distribution and disease associations. The Journal of Steroid Biochemistry and Molecular Biology, 175, 102-107.

15. Jo, W. S., Cho, E. H., Kang, B. J., Kwon, G. D., Ha, Y. C., Jang, S., \& Kim, H. Y. (2018). The impact of educational interventions on osteoporosis knowledge among Korean osteoporosis patients. Journal of bone metabolism, 25(2), 115-121.

16. Brecher, L. S., Pomerantz, S. C., Snyder, B. A., Janora, D. M., Klotzbach-Shimomura, K. M., \& Cavalieri, T. A. (2002). Osteoporosis prevention project: a model multidisciplinary educational intervention. The Journal of the American Osteopathic Association, 102(6), 327-335.

17. Laslett, L. L., Lynch, J., Sullivan, T. R., \& McNEIL, J. D. (2011). Osteoporosis education improves osteoporosis knowledge and dietary calcium: comparison of a 4 week and a one- session education course. International Journal of Rheumatic Diseases, 14(3), 239-247.

18. Winzenberg, T. M., Oldenburg, B., Frendin, S., De Wit, L., \& Jones, G. (2005). Effects of bone density feedback and group education on osteoporosis knowledge and osteoporosis self-efficacy in premenopausal women: a randomized controlled trial. Journal of Clinical Densitometry, 8(1), 95-103.

19. Francis, K. L., Matthews, B. L., Van Mechelen, W., Bennell, K. L., \& Osborne, R. H. (2009). Effectiveness of a community-based osteoporosis education and self-management course: a wait list controlled trial. Osteoporosis international, 20(9), 1563-1570. 
20. Kasper, M. J., Peterson, M. G., \& Allegrante, J. P. (2001). The need for comprehensive educational osteoporosis prevention programs for young women: results from a second osteoporosis prevention survey. Arthritis Care \& Research: Official Journal of the American College of Rheumatology, 45(1), 28-34.

21. Hernandez-Rauda, R., \& Martinez-Garcia, S. (2004). Osteoporosis-related life habits and knowledge about osteoporosis among women in El Salvador: A cross-sectional study. BMC musculoskeletal disorders, 5(1), 29.

22. Saw, S. M., Hong, C. Y., Lee, J., Wong, M. L., Chan, M. F., Cheng, A., \& Leong, K. H. (2003). Awareness and health beliefs of women towards osteoporosis. Osteoporosis International, 14(7), 595-601.

23. Etemadifar, M. R., Nourian, S. M., Fereidan-Esfahani, M., Shemshaki, H., Nourbakhsh, M., \& Zarezadeh, A. (2013). Relationship of knowledge about osteoporosis with education level and life habits. World journal of orthopedics, 4(3), 139-143.

Citation: Sahbanathul Missiriya Jalal (2021). Effect of Osteoporosis Prevention Programme on Knowledge among Elderly People. South Asian Res J App Med Sci, 3(1), 1-5. 